\title{
Dromedary camel CD14high MHCllhigh monocytes display inflammatory properties and are reduced in newborn camel calves
}

Jamal Hussen ( $\nabla$ jhussen@kfu.edu.sa )

King Faisal University https://orcid.org/0000-0001-8942-005X

Turke Shawaf

King Faisal University

Abdullah I. A. Al-Mubarak

King Faisal University

Naser Abdallah Al Humam

King Faisal University

\section{Faisal Almathen}

King Faisal University

Hans-Joachim Schuberth

Tierarztliche Hochschule Hannover

Research article

Keywords: dromedary camel; monocyte subsets; flow cytometry; phagocytosis; adhesion molecules

Posted Date: October 10th, 2019

DOI: https://doi.org/10.21203/rs.2.15871/v1

License: (9) (i) This work is licensed under a Creative Commons Attribution 4.0 International License.

Read Full License

Version of Record: A version of this preprint was published at BMC Veterinary Research on February 18th, 2020. See the published version at https://doi.org/10.1186/s12917-020-02285-8. 


\section{Abstract}

Background in human and different animal species, blood monocytes are classified based on their expression pattern of different monocytic markers into phenotypically and functionally different subsets. In the current study, we used monoclonal antibodies to CD172a, CD14, CD163 and MHCII to identify monocyte subsets in peripheral blood of dromedary camels and to evaluate their phenotype and function. Results similar to bovine and swine monocytes, camel CD172a can be used as a pan-monocyte marker. Based on CD14, CD163 and MHCll expression, camel CD172a+ monocytes were divided into three subsets: The major subpopulation of camel monocytes (mo-I) showed high expression of CD14 and CD163, but low expression of MHCII. A second subset of monocytes (mo-II) expressed highly all three markers, CD14, CD163 and MHCII. A third monocyte subset (mo-III) displayed low expression of CD14 and CD163 with high MHCll expression. The three monocyte subsets also showed different expression patterns of cell adhesion molecules. While the two MHCII high subsets (mo-II and mo-III) showed higher expression of CD11a in comparison to the MHClllow subset mo-I, CD18 and CD11b were highest expressed on the two CD14high subsets (mo-I and mo-II). Bacterial stimulation of camel leukocytes identified mo-ll cells as an antimicrobial monocyte subset with the highest phagocytic and ROS production capacity. The comparison of monocyte counts and phenotype between newborn camel calves and adult camels revealed significantly reduced numbers of mo-Il cells in newborn animals. Monocytes of newborns expressed significantly more CD172a and CD163 molecules but less CD14 and MHCII molecules than monocytes of adult camels.Conclusions The analysis of phenotypic and functional properties suggests that camel monocyte subsets mo-I, mo-II and mo-III are counterparts of bovine classical, intermediate and non-classical monocytes respectively. Age related changes in camel monocyte numbers and phenotype were identified.

\section{Background}

Blood monocytes are innate immune cells with essential role in the defense against pathogens [1]. Monocytes are equipped with a vast array of receptors that mediate pathogen recognition, phagocytosis and subsequent production of reactive oxygen species (ROS) $[2,3]$.

Studies in humans [4], mice [5], cows [6-8], pigs [9] and dogs [10] have classified monocytes into different subsets with subset-specific phenotype and function [11]. In human and cattle, monocytes were classified based on their CD14 and CD16 expression into CD14 ${ }^{++}$CD16 ${ }^{-}$classical monocytes (90 \% of total monocytes), $\mathrm{CD}_{14}{ }^{++} \mathrm{CD} 16^{+}$intermediate monocytes (5\% of total monocytes) and CD $14^{+} \mathrm{CD} 16^{++}$nonclassical monocytes (5 \% of total monocytes) [7, 12]. However, in species, where CD14 expression is low, like in the mouse, [5], or where no cross-reactive antibodies against CD16 are available, like in the dog [10], other surface molecules have been used for the classification of blood monocytes. In the mouse, the myeloid markers Ly6C and CD43 were used for the analysis of monocyte heterogeneity [13]. The identification of monocyte subsets in the pig was based on the differential expression of CD14 and CD163 $[9,14]$. Dog monocytes were divided into three monocyte subsets based on CD14 and MHCII molecules expression patterns [10]. 
Monocyte subsets showed phenotypic and functional differences in a species-specific manner. This includes the expression of different monocytic markers, cell adhesion molecules, cytokines and chemokine receptors $[11,15]$. In addition, many functional differences have been identified between monocyte subsets. Human and bovine $\mathrm{CD} 14^{\text {high }}$ monocytes, including classical and intermediate monocytes, showed enhanced anti-bacterial activity, including phagocytosis and ROS generation capacity $[6,12]$, whereas a patrolling function along the endothelium and a role in anti-viral immunity have been described for human and mouse CD14 ${ }^{\text {low }}$ monocytes (non-classical monocytes) [16].

To our knowledge, there are no studies on the heterogeneity of blood monocytes in dromedary camels. Therefore, this study aimed at the analysis of phenotype and function of camel blood monocytes and the identification of monocyte subsets in newborn and adult camels.

\section{Materials And Methods}

\subsection{Animals}

Blood samples were collected from clinically healthy camels (Camelus dromedaries) at the Camel Research Center, King Faisal University, Saudi Arabia. The involved animals included 23 newborn camel calves (aged < four weeks) and 62 adult camels aged between 4 and 10 years. Blood was obtained by venepuncture of the vena jugularis externa into vacutainer tubes containing EDTA (Becton Dickinson, Heidelberg, Germany). All experimental procedures and management conditions used in this study were approved by the Ethics Committee at King Faisal University, Saudi Arabia (Permission number DSR 1811001).

\subsection{Hypotonic lysis and separation of whole blood leukocytes}

Separation of whole camel leukocytes was done after hypotonic lysis of blood erythrocytes [17]. Briefly, blood was suspended in distilled water for $20 \mathrm{sec}$ and double concentrated PBS was added to restore tonicity. This was repeated until complete erythrolysis. Separated cells were finally suspended in MIF buffer (PBS containing bovine serum albumin $(5 \mathrm{~g} / \mathrm{L})$ and $\left.\mathrm{NaN}_{3}(0.1 \mathrm{~g} / \mathrm{L})\right)$ at $5 \times 10^{6} \mathrm{cells} / \mathrm{ml}$. The mean viability of separated cells was evaluated flow cytometrically by dye exclusion (propidium iodide; $2 \mu \mathrm{g} / \mathrm{ml}$, Calbiochem, Germany) and consistently $>95 \%$.

\subsection{Monoclonal antibodies}

Monoclonal antibodies used in this study are listed in table 1.

\subsection{Flow cytometric analysis of camel blood monocytes}

The identification of camel monocyte subsets and the analysis of the subset-specific expression pattern of monocytic markers and adhesion molecules were performed after direct and indirect labeling of cells with surface molecule-specific antibodies and flow cytometrical analysis [18]. Separated camel 
leukocytes $\left(5 \times 10^{6}\right.$ cells / ml) were incubated in 96 well round-bottom microtiter plates $\left(1 \times 10^{6} /\right.$ well; 20 min; $4^{\circ} \mathrm{C}$ ), in a three-step staining process, with monoclonal antibodies specific for CD172a, MHCII and CD163 (in the following two combinations: CD172a; MHCIl; CD14 and CD163; MHCIl; CD14) or with isotype control antibodies in PBS containing bovine serum albumin $(5 \mathrm{~g} / \mathrm{L})$ and $\mathrm{NaN}_{3}(0.1 \mathrm{~g} / \mathrm{L})$. After incubation, cells were washed twice and incubated with mouse secondary antibodies IgG1, IgG2a (BD) labelled with different fluorochromes. In a third labelling step, after washing the cells, directly labeled monoclonal antibodies to CD14, CD11a, CD11b, and CD18 were added. Finally, cells were washed and analyzed by flow cytometry. For each measurement 100000 events were acquired. Flow cytometric data were analyzed with the software FlowJo version 10 (FLOWJO LLC).

\subsection{Generation of reactive oxygen species (ROS)}

ROS generation was performed in 96-well round-bottom microtiter plates (Corning, NY, USA) as described earlier [19] with modifications. Separated camel leukocytes $\left(1 \times 10^{6} /\right.$ well) in RPMI medium were incubated with heat killed staphylococcus aureus (50 bacteria/cell) for $20 \mathrm{~min}\left(37^{\circ} \mathrm{C}, 5 \% \mathrm{CO}_{2}\right)$. For the detection of ROS, dihydrorhodamine (DHR) 123 (Mobitec, Goettingen, Germany) was added to the cells (150 ng / ml final). To identify monocyte subsets, cells were labeled with monoclonal antibodies to CD14 and MHCII (see above). After washing, cells were analyzed by flow cytometry (FACSCalibur, Becton Dickinson Biosciences, San Jose, California, USA). The relative amount of generated ROS was determined by the mean green fluorescence intensity of gated monocyte subsets (based on CD14 and MHCIl expression) after acquisition of 100000 events ( $n=15$ animals).

\subsection{Phagocytosis assay}

Heat killed staphylococcus aureus (S. aureus) bacteria (Pansorbin, Calbiochem, Merck, Nottingham, UK) were labeled with fluoresceinisothiocyanate (FITC, Sigma-Aldrich, St. Louis, Missouri, USA). FITCconjugated and heat killed $S$. aureus bacteria were suspended in RPMI medium and adjusted to $2 \times 10^{8}$ bacteria / $\mathrm{ml}$. Separated camel leukocytes were plated in 96 well plates $\left(1 \times 10^{6} /\right.$ well $)$ and incubated $\left(37^{\circ} \mathrm{C}\right.$, $\left.5 \% \mathrm{CO}_{2}\right)$ with labeled bacteria (50 bacteria / cell) for 40 minutes $\left(37^{\circ} \mathrm{C}, 5 \% \mathrm{CO}_{2}\right)$. To identify monocyte subsets, cells were labeled with monoclonal antibodies to CD14 and MHCII (see above). After washing, cells were analyzed by flow cytometry (FACSCalibur, Becton Dickinson Biosciences, San Jose, California, USA). After washing, cells were analyzed by flow cytometry (FACSCalibur, Becton Dickinson Biosciences, San Jose, California, USA). For each monocyte subset (based on their CD14 and MHCII expression), phagocytosis-positive cells were defined as the percentage of green fluorescing cells among total cells ( $n=15$ animals). Phagocytosis capacity (as an indicator for the number of bacteria ingested by each monocyte) was defined as the mean green fluorescence intensity of gated phagocytosis-positive monocyte subset.

\section{Statistical Analyses}


For statistical analysis, the software Prism (GraphPad) was used. Results are expressed as means \pm S.E. of the mean (SEM). For the comparison between means of two groups, the t-test was used. Differences between means of more than two groups were tested with one-factorial analysis of variance (ANOVA) and Bonferroni's correction for normally distributed data. Results were considered statistically significant at a p-value of less than 0.05 .

\section{Results}

\subsection{Phenotypic characterization of camel monocytes}

Camel monocytes were identified based on their FSC/SSC characteristics (Fig. 1A) and CD172a expression (Fig. 1B). Since no tested antibody specific for CD16 cross-reacted with camel CD16 (data not shown), antibodies specific for CD14, CD163 and MHCll were used to identify camel monocyte subsets. Based on the cell surface expression of CD14 and MHCII, three monocyte subsets were defined after flow cytometry (Fig. 1C). The major subpopulation of camel monocytes (mo-l) showed high expression of CD14 and CD163, but low expression of MHCII (CD14 ${ }^{\text {high }}{ }^{2}$ 163 ${ }^{\text {high }} \mathrm{MHClI}^{\text {low }}$ ) (Fig. 2). A second subset of monocytes (mo-II) expressed all three markers at a high density (CD14 ${ }^{\text {high }}{ }^{C D} 163^{\text {high }}{ }^{\mathrm{MHCII}}{ }^{\text {high }}$ ). A third monocyte subset (mo-III) displayed low expression of CD14 and CD163 with high MHCII expression (CD14 ${ }^{\text {low }} \mathrm{CD} 163^{\text {low }} \mathrm{MHCI}{ }^{\text {high }}$ ) (Fig. 2), which was higher than MHCIl expression on mo-I but lower than $\mathrm{MHCll}$ expression on mo-II (Fig. 2B). Although all subsets expressed high levels of CD172a, the expression level of CD172a was significantly higher on mo-II cells compared with mo-I ans Mo-II monocytes (Fig.2B).

\subsection{Camel monocyte subsets differ in size and complexity}

The flow cytometrically determined mean forward scatter (correlated with size) and the mean side scatter (correlated with complexity) of camel monocyte subsets revealed, that camel mo-Il cells were significantly bigger compared to mo-I and mo-II cells (Fig. 3A). The three monocytes subsets displayed no significant differences in complexity (Fig. 3B).

\subsection{Distribution of monocyte subsets in blood of dromedary camel}

With $86.4 \% \pm 0.7 \%$ among CD172a+ monocytes, camel mo-I monocytes represented the main monocyte population in blood, whereas the other two subsets mo-II $(6.8 \% \pm 0.3 \%)$ and III $(5.0 \% \pm 0.3 \%)$ represented minor minor fractions among blood monocytes (Tab. 2).

\subsection{Camel monocytes differ in their expression pattern of cell adhesion molecules}

Camel monocyte subsets significantly differed in their expression patterns of adhesion molecules. While the two MHCII ${ }^{\text {high }}$ subsets (mo-II and mo-III) showed higher expression of CD11a in comparison to the $\mathrm{MHCII}^{\text {low }}$ subset (mo-I), CD18 was highest expressed on the two CD14 ${ }^{\text {high }}$ subsets. CD14 ${ }^{\text {high }} / \mathrm{MHCI}^{\text {high }}$ 
monocytes showed the highest expression of CD11b. However CD11b expression was higher on mo-I monocytes compared to the mo-lll subset (Fig. 4).

\subsection{Camel monocyte subsets differ in their antimicrobial activity}

Antimicrobial activity of camel monocyte subsets was investigated by the capacity of each subset to ingest bacteria (phagocytosis) and to produce reactive oxygen species upon bacterial stimulation in vitro. Among the two CD14 high subsets (mo-l, mo-II), the percentage of phagocytosis-positive cells was about twice higher than for the CD14 ${ }^{\text {low }}$ subset (mo-III) (Fig. 5A). The mean fluorescence intensity of phagocytosis-positive cells as an indicator for the number of bacteria phagocytosed per cell was highest for the CD14 ${ }^{\text {high }} \mathrm{MHCI}^{\text {high }}$ subset (mo-II) (Fig. 5B). ROS production activity after bacterial stimulation followed the same pattern with mo-ll cells showing significantly more ROS production compared to mo-I and mo-III monocytes (Fig. 5C).

\subsection{Monocyte subsets in newborn and adult camels differ in composition and phenotype}

The total number of circulating monocytes in blood was significantly higher in newborn (< one month of age) camel calves $\left(1453 \pm 169 \times 10^{3} \mathrm{cell} / \mathrm{ml}\right)$ when compared with monocyte number in adult $(4-10$ years) camels $\left(947 \pm 53 \times 10^{3} \mathrm{cell} / \mathrm{ml}\right)$ (Fig. $\left.6 \mathrm{~A}\right)$. Among all monocytes, the fraction as well as the absolute numbers of mo-I monocytes were significantly higher in newborns than in adults (Fig. 6B). Although the fraction of mo-Ill cells among all monocytes was comparable between newborns and adults, absolute mo-III numbers were significantly higher in newborns (Fig. 6B). Compared with adult camels, newborns showed up with significantly lower numbers of mo-ll and a significantly lower percentage of mo-ll cells among all monocytes (Fig. 6B).

Comparing the expressed density of expressed monocyte surface molecules, monocytes of newborn camels significantly expressed more CD172a and CD163 molecules whereas the expression of CD14 and MHCIl was significantly lower than on monocytes of adult camels (Fig 7).

\section{Discussion}

Studies in different species revealed that monocytes are a heterogeneous population of innate immune cells consisting of phenotypically and functionally different subsets [4-11]. The clinical relevance of distinct monocyte subsets has been recently demonstrated for different species by linking the distribution of blood monocyte subsets to the susceptibility to different infectious [20] and non-infectious diseases $[21,22]$.

Although in most studied species monocyte subsets were identified based on the expression of the surface markers CD14 and CD16 [7, 12], other surface markers were used for monocyte classification in some species due to low CD14 expression [5] or unavailability of CD16 antibodies [10]. As no crossreactive antibodies to camel CD16 were available [17], we used monoclonal antibodies to the monocytic markers CD172a, CD14, MHCII and CD163 to analyze the existence of monocyte subsets in camel blood. 
The signal-regulatory protein alpha (SIRPalpha), also known as CD172a, which was highly expressed on camel monocytes, was used to identify total camel monocytes. This is in line with studies in the pig and bovines, where CD172a is characterized as a pan monocyte marker [6-8, 14, 23]. Although CD172a is also expressed at low levels on plasmacytoid DC [24, 25], CD172a-positive camel monocyte subsets are distinct from blood dendritic cells, which are negative for both CD14 and CD163 [26].

Staining with $\mathrm{CD} 172 \mathrm{a}, \mathrm{CD} 14$ and $\mathrm{MHCl}$ antibodies identified three CD172a-positve camel subsets: CD14 ${ }^{\text {high }} \mathrm{MHCII}^{\text {low }}$ (subset mo-I), CD14 ${ }^{\text {high }} \mathrm{MHCII}^{\text {high }}$ (subset mo-II) and CD14 ${ }^{\text {low }} \mathrm{MHCII}^{\text {high }}$ monocytes (subset mo-III). A direct comparison of camel monocyte subsets with those in the human or bovine system is not possible due to the lack of camel-specific CD16 antibodies. Indirectly, based on their high CD14 and CD163 expression, their low MHCll expression together with their percentage in blood ( $87 \%$ of total monocytes), camel monocytes mo-I are very likely equivalent to bovine and human classical monocytes [7, 12]. Camel monocytes mo-Il, due to their highest expression of MHCll and their of high level expression of CD14 and CD163 can be suggested as equivalents to human and bovine intermediate monocytes. This is also supported by the anti-bacterial and inflammatory nature of mo-Il cells, as they showed the highest phagocytosis activity among camel monocytes and ROS generation activity in comparison to the other two camel subsets. These functional activities are also comparable with the inflammatory nature of bovine intermediate monocytes $[6,11]$. The low expression density of CD14 and CD163 and the high expression of MHCII on the camel mo-III monocytes strongly suggest that this camel monocyte subset represents a counterpart of bovine non-classical monocytes. This is supported by their highest expression of adhesion molecule leukocyte functional antigen 1 (LFA-1 or CD11a) and the low level expression density of the adhesion molecules CD18 and Mac1 (CD11b) on camel mo-III cells, which is comparable to the bovine system [7,27]. In addition, the low phagocytic and ROS generation activity of camel mo-III monocytes is in line with findings reported for bovine non-classical monocytes [6].

The demonstrated phenotypical characteristics of camel monocytes seem to change during ontogeny since significant differences between monocytes of newborn and adult camels were obtained. Newborn camels showed significantly higher total monocyte numbers and numbers of mo-I and mo-III cells in blood whereas mo-ll cells were less abundant in blood of newborns compared to adults. . Whether these differences are associated with a different equipment with chemokine receptors and hence a different migration behavior into tissues or whether this reflects differences in maturation/release processes from the bone marrow can only be hypothesized. The different expression densities of monocyte-related surface molecules between newborn and adult camels (Fig. 7) may support this idea. Altogether these findings demonstrate age related effects on the distribution and phenotype of camel monocyte subsets, which may contribute to an altered and functions of the newborn innate immune system [28].

In summary, we identified three monocyte subsets in dromedary camel blood based on the surface expression of CD14, CD163 and MHCIl: camel monocyte subset mo-I (CD14 $\left.{ }^{\text {high }} \mathrm{MHCll}^{\text {low }}\right)$, camel monocyte subset mo-II (CD14 $\left.{ }^{\text {high }} \mathrm{MHCII}^{\text {high }}\right)$ and camel monocyte subset mo-III (CD14 $\left.{ }^{\text {low } M H C I I}{ }^{\text {high }}\right)$. The analysis of phenotypic and functional properties suggests that camel monocyte subsets mo-I, mo-II and 
mo-III are counterparts of bovine classical, intermediate and non-classical monocytes respectively. Age related changes in camel monocyte numbers and phenotype were identified.

\section{Declarations}

\section{Ethics approval and consent to participate}

All experimental procedures and management conditions used in this study were approved by the Ethics Committee at King Faisal University, Saudi Arabia (Permission number DSR 1811001).

\section{Consent for publication}

Not applicable

\section{Availability of data and materials}

The datasets used and/or analysed during the current study are available from the corresponding author on reasonable request.

\section{Competing interests}

The authors declare that they have no competing interests.

\section{Funding}

The study was funded by the Deanship of Scientific Research at King Faisal University (Project number 1811001).

\section{Authors' contributions}

$\mathrm{JH}, \mathrm{HJ}$ conceived and designed the study. JH, TS and FA collected the samples from the animals. JH, NA and AIA prepared the samples for flow cytometry. JH, NA, AIA and FA analyzed the labelled cells by flow cytometry. JH, TS and HJ analyzed the data by Flow Jo. All authors read and approved the final manuscript.

\section{Acknowledgements}

The researchers thanks the Deanship of Scientific Research at King Faisal University for funding this research (Project number 1811001).

\section{Conflict of interest:}

None.

\section{References}


1. Jakubzick CV, Randolph GJ, Henson PM: Monocyte differentiation and antigen-presenting functions. Nat Rev Immunol 2017, 17(6):349-362.

2. Auffray C, Fogg D, Garfa M, Elain G, Join-Lambert O, Kayal S, Sarnacki S, Cumano A, Lauvau G, Geissmann F: Monitoring of blood vessels and tissues by a population of monocytes with patrolling behavior. Science 2007, 317(5838):666-670.

3. Ziegler-Heitbrock HW: Definition of human blood monocytes. J Leukoc Bio/ 2000, 67(5):603-606.

4. Gordon S, Taylor PR: Monocyte and macrophage heterogeneity. Nat Rev Immuno/2005, 5(12):953964.

5. Ingersoll MA, Spanbroek R, Lottaz C, Gautier EL, Frankenberger M, Hoffmann R, Lang R, Haniffa M, Collin $\mathrm{M}$, Tacke $\mathrm{F}$ et al: Comparison of gene expression profiles between human and mouse monocyte subsets. Blood 2010, 115(3):e10-19.

6. Hussen J, Duvel A, Sandra O, Smith D, Sheldon IM, Zieger P, Schuberth HJ: Phenotypic and functional heterogeneity of bovine blood monocytes. PLoS One 2013, 8(8):e71502.

7. Hussen J, Schuberth HJ: Heterogeneity of Bovine Peripheral Blood Monocytes. Front Immunol 2017, 8:1875.

8. Corripio-Miyar Y, Hope J, Mclnnes CJ, Wattegedera SR, Jensen K, Pang Y, Entrican G, Glass EJ: Phenotypic and functional analysis of monocyte populations in cattle peripheral blood identifies a subset with high endocytic and allogeneic T-cell stimulatory capacity. Vet Res 2015, 46:112.

9. Fairbairn L, Kapetanovic R, Beraldi D, Sester DP, Tuggle CK, Archibald AL, Hume DA: Comparative analysis of monocyte subsets in the pig. J Immunol 2013, 190(12):6389-6396.

10. Gibbons N, Goulart MR, Chang YM, Efstathiou K, Purcell R, Wu Y, Peters LM, Turmaine M, Szladovits $B$, Garden OA: Phenotypic heterogeneity of peripheral monocytes in healthy dogs. Veterinary immunology and immunopathology 2017, 190:26-30.

11. Ziegler-Heitbrock L: Monocyte subsets in man and other species. Cell Immuno/ 2014, 289(1-2):135139.

12. Ziegler-Heitbrock L, Ancuta P, Crowe S, Dalod M, Grau V, Hart DN, Leenen PJ, Liu YJ, MacPherson G, Randolph GJ et al: Nomenclature of monocytes and dendritic cells in blood. Blood 2010, 116(16):e74-80.

13. Zawada AM, Rogacev KS, Schirmer SH, Sester M, Bohm M, Fliser D, Heine GH: Monocyte heterogeneity in human cardiovascular disease. Immunobiology 2012.

14. Moreno S, Alvarez B, Poderoso T, Revilla C, Ezquerra A, Alonso F, Dominguez J: Porcine monocyte subsets differ in the expression of CCR2 and in their responsiveness to CCL2. Vet Res 2010, 41(5):76.

15. Ziegler-Heitbrock L: Reprint of: Monocyte subsets in man and other species. Cell Immuno/2014, 291(1-2):11-15.

16. Cros J, Cagnard N, Woollard K, Patey N, Zhang SY, Senechal B, Puel A, Biswas SK, Moshous D, Picard $C$ et al: Human CD14dim monocytes patrol and sense nucleic acids and viruses via TLR7 and TLR8 receptors. Immunity 2010, 33(3):375-386. 
17. Hussen J, Shawaf T, Al-Herz Al, Alturaifi HR, Alluwaimi AM: Reactivity of commercially available monoclonal antibodies to human $\mathrm{CD}$ antigens with peripheral blood leucocytes of dromedary camels (Camelus dromedarius). Open Vet $J$ 2017, 7(2):150-153.

18. Eger M, Hussen J, Drong C, Meyer U, von Soosten D, Frahm J, Daenicke S, Breves G, Schuberth HJ: Impacts of parturition and body condition score on glucose uptake capacity of bovine monocyte subsets. Vet Immunol Immunopathol 2015, 166(1-2):33-42.

19. Hussen $\mathrm{HI}$, Persson M, Moradi $\mathrm{T}$ : The trends and the risk of type 1 diabetes over the past 40 years: an analysis by birth cohorts and by parental migration background in Sweden. BMJ Open 2013, 3(10): $\mathrm{e} 003418$.

20. Pomeroy B, Sipka A, Hussen J, Eger M, Schukken Y, Schuberth HJ: Counts of bovine monocyte subsets prior to calving are predictive for postpartum occurrence of mastitis and metritis. Vet Res 2017, 48(1):13.

21. Wong KL, Yeap WH, Tai JJ, Ong SM, Dang TM, Wong SC: The three human monocyte subsets: implications for health and disease. Immunol Res 2012, 53(1-3):41-57.

22. Stansfield BK, Ingram DA: Clinical significance of monocyte heterogeneity. Clin Trans/ Med 2015, 4:5.

23. Chamorro S, Revilla C, Alvarez B, Alonso F, Ezquerra A, Dominguez J: Phenotypic and functional heterogeneity of porcine blood monocytes and its relation with maturation. Immunology 2005 , 114(1):63-71.

24. Gibson A, Miah S, Griebel P, Brownlie J, Werling D: Identification of a lineage negative cell population in bovine peripheral blood with the ability to mount a strong type I interferon response. Dev Comp Immunol 2012, 36(2):332-341.

25. Summerfield A, Guzylack-Piriou L, Schaub A, Carrasco CP, Tache V, Charley B, McCullough KC: Porcine peripheral blood dendritic cells and natural interferon-producing cells. Immunology 2003, 110(4):440-449.

26. Auffray C, Sieweke MH, Geissmann F: Blood monocytes: development, heterogeneity, and relationship with dendritic cells. Annu Rev Immunol 2009, 27:669-692.

27. Hussen J, Koy M, Petzl W, Schuberth HJ: Neutrophil degranulation differentially modulates phenotype and function of bovine monocyte subsets. Innate Immun 2016, 22(2):124-137.

28. Philbin VJ, Levy O: Developmental biology of the innate immune response: implications for neonatal and infant vaccine development. Pediatr Res 2009, 65(5 Pt 2):98R-105R.

\section{Tables}

Table 1. List of antibodies 


\begin{tabular}{lllll}
\hline Antigen & Antibody clone & Labelling & Source & Isotype \\
\hline CD172a & DH59b & - & WSU & mlgG1 \\
CD14 & TÜK4 & PerCP & Biorad & mlgG2a \\
\hline CD14 & TÜK4 & APC & Biorad & mlgG2a \\
\hline CD163 & LND68A & - & WSU & mlgG1 \\
\hline MHCII & TH81A5 & - & WSU & mlgG2a \\
\hline CD11a & G43-25B & PE & BD & mlgG2a \\
\hline CD11b & ICRF44 & PE-Cy7 & BD & mlgG1 \\
\hline CD18 & 6.7 & FITC & BD & mlgG1 \\
\hline mlgG2a & polyclonal & PE & Invitrogen & glgG \\
\hline mlgG1 & polyclonal & FITC & Invitrogen & glgG \\
\hline
\end{tabular}

Ig: Immunoglobulin; m: mouse; MHC-II: Major Histocompatibility Complex class II, g: goat, WSU: Washington State University.

Table. 2. Relative and absolute distribution of monocyte subsets in camel peripheral blood.

\begin{tabular}{|c|c|c|c|}
\hline & $\mathrm{CD}_{14}{ }^{\text {high }} \mathrm{MHCIl}$ low & $\mathrm{CD} 14^{\text {high }} \mathrm{MHCII}^{\text {high }}$ & $\mathrm{CD} 14^{\text {low }} \mathrm{MHCII}{ }^{\text {high }}$ \\
\hline$\%$ of all monocytes & $86.4 \pm 0.7$ & $6.8 \pm 0.3$ & $5.0 \pm 0.3$ \\
\hline Cells $/ \mathrm{ml}$ blood $\left(\times 10^{3}\right)$ & $627.8 \pm 27.1$ & $80.1 \pm 7.1$ & $48.4 \pm 5.0$ \\
\hline
\end{tabular}

Means \pm SEM, Blood of 60 animals was analyzed.

Figures 
A)

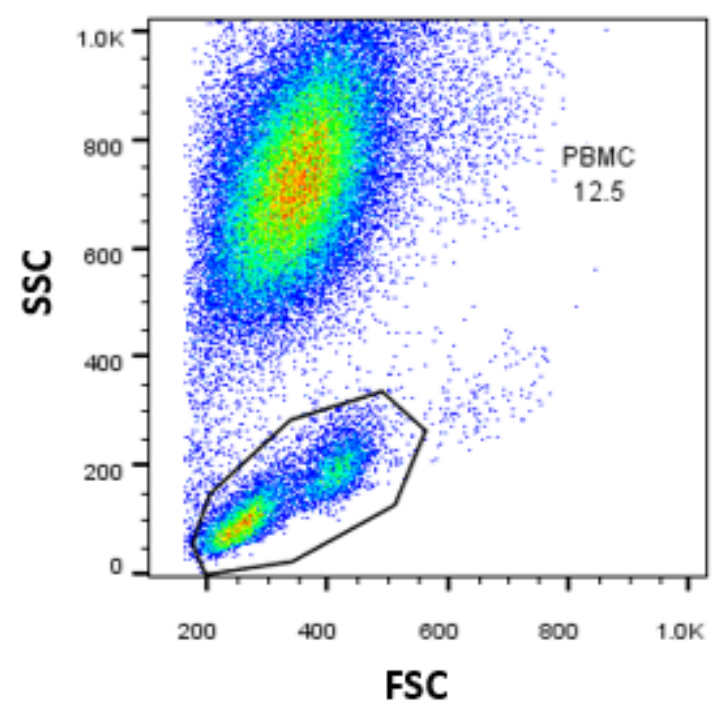

C)

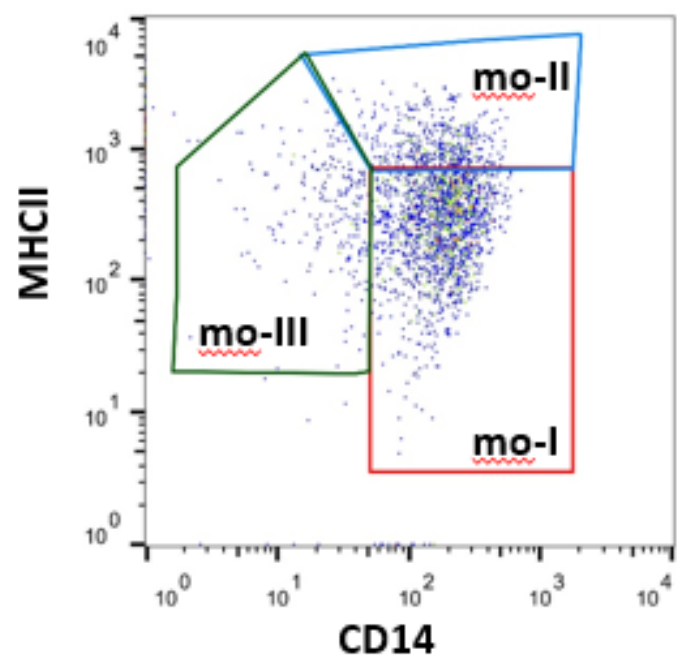

B)

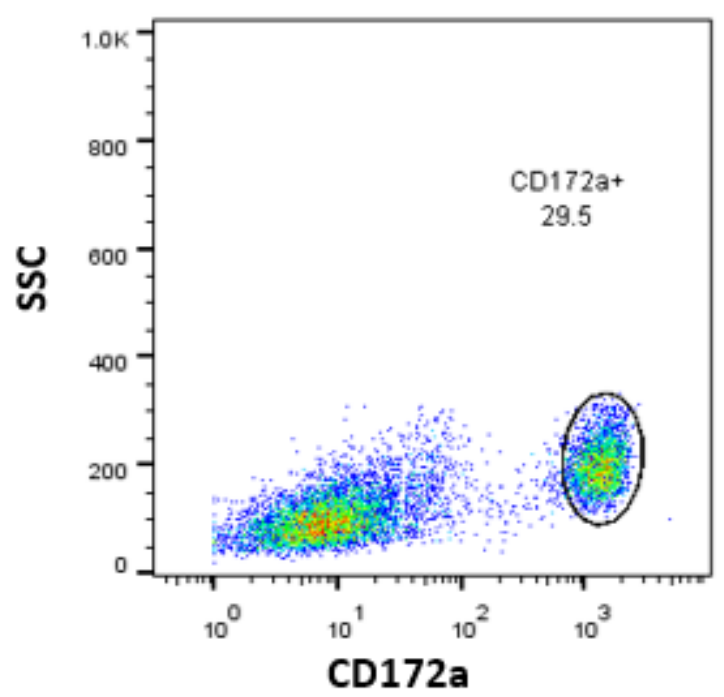

\section{Figure 1}

Gating strategy of camel monocyte subsets. Camel leukocytes were separated by hypotonic lysis of erythrocytes and separated cells were labeled with monoclonal antibodies to CD14, CD172a and MHCII molecules and analyzed by flow cytometry. A) Mononuclear cells (MNC, encircled region) were identified based on their forward (FSC) and side scatter (SSC) properties. B) In a SSC vs CD172a dot plot of gated MNC, a region was set on CD172a-positive monocytes). C) Correlated dot plots of CD14 versus MHCII fluorescence after gating on CD172a-positive cells. Monocyte subsets mo I, II, and III were identified according to their CD14 and MHCll expression density (mo-l: CD14highMHCllow, mo-ll: CD14highMHCllhigh, mo-III: CD14lowMHCllhigh). 
A)

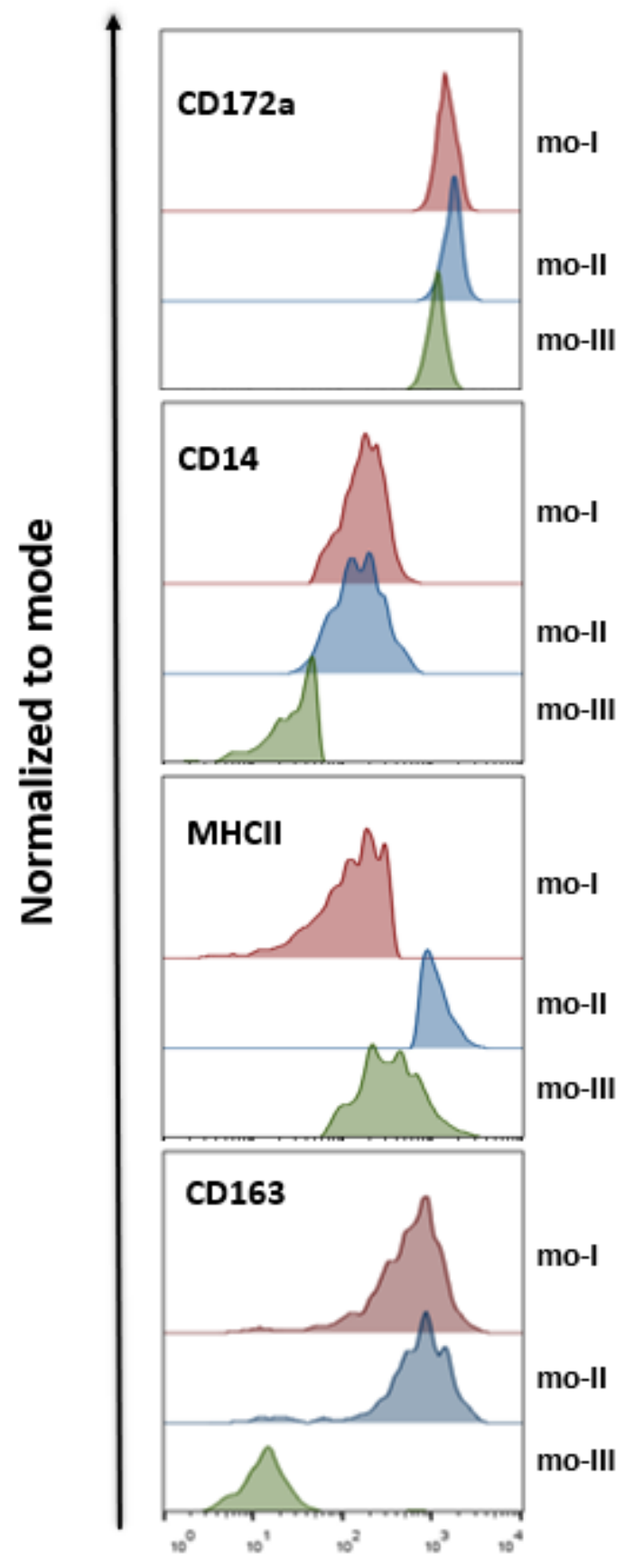

Fluorescence intensity
B)
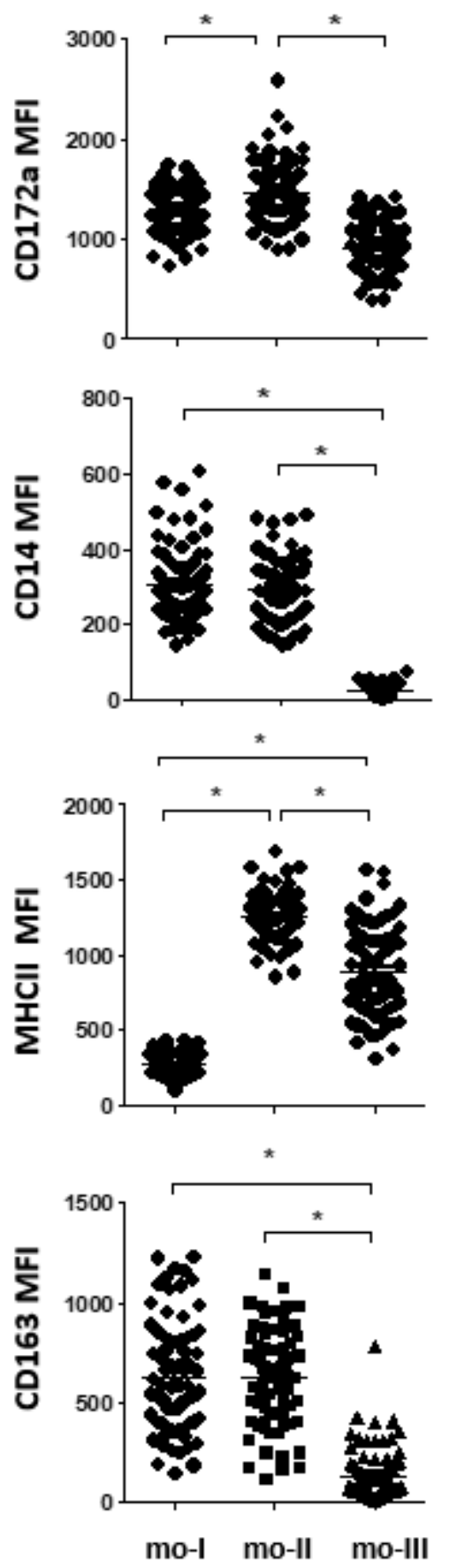

Figure 2

Differential expression of cell surface molecules on camel monocyte subsets. (A) Separated camel leukocytes were labelled with monoclonal antibodies to CD14, CD172a, MHCII and CD163 in different combinations and were analysed by flow cytometry. After setting gates on camel monocyte subsets (based on CD14 and MHCIl expression), expression levels of CD14, CD172a, MHCII and CD163 are shown as histograms. (B) Comparison of mean fluorescence intensities between the camel monocyte subsets 
mo-I, mo-II and mo-III of analysed markers were graphically displayed. * indicates a significant difference ( $p$ value $<0.05$ ) between groups as analysed by the one-way analysis of variance (ANOVA).

A)

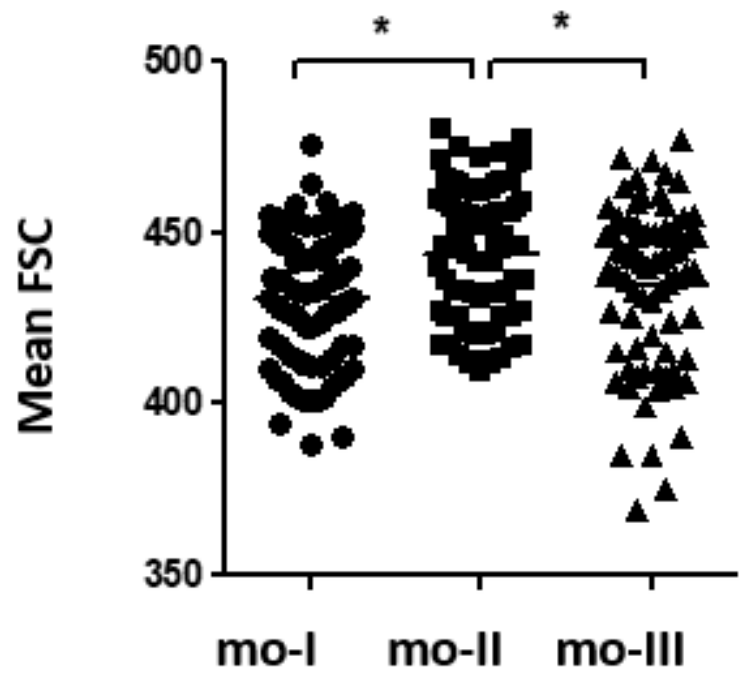

B)

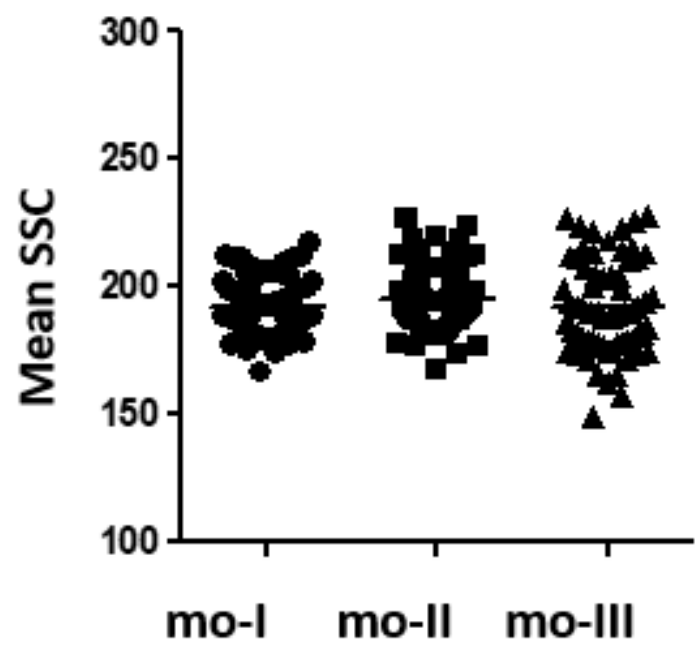

Figure 3

Size and complexity of camel monocyte subsets. Camel leukocytes were labelled with monoclonal antibodies to CD14, CD172a and MHCII and were analysed by flow cytometry. After gating on camel monocyte subsets mo-I, mo-II, and mo-III, their mean size (A, forward scatter, FSC) and mean complexity (B, side scatter, SSC) was determined and graphically displayed. * indicates a significant difference ( $p$ value $<0.05)$ between groups as analysed by the one-way analysis of variance (ANOVA). 

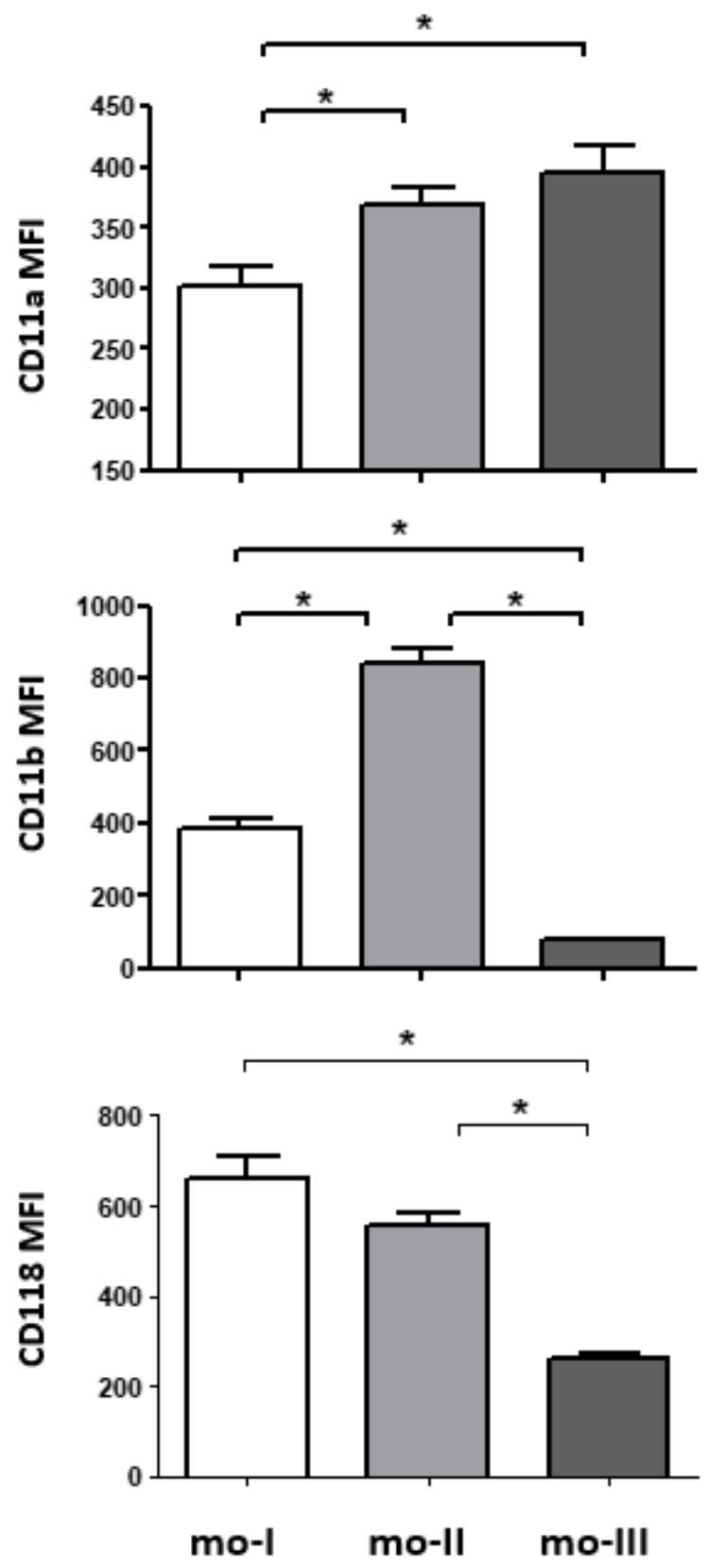

Figure 4

Expression densities of cell surface adhesion molecules on camel monocyte subsets. Separated camel leukocytes were labelled with monoclonal antibodies to CD14, MHCII, CD11a, CD11b or CD18 and were analysed by flow cytometry. After gating on camel monocyte subsets (mo-I, mo-II, mo-III), expression levels of CD11a, CD11b and CD18 were calculated as mean fluorescence intensities (mean \pm SEM , $n=62$ animals). * indicates a significant difference ( $p$ value $<0.05)$ between groups as analysed by the one-way analysis of variance (ANOVA). 
A)

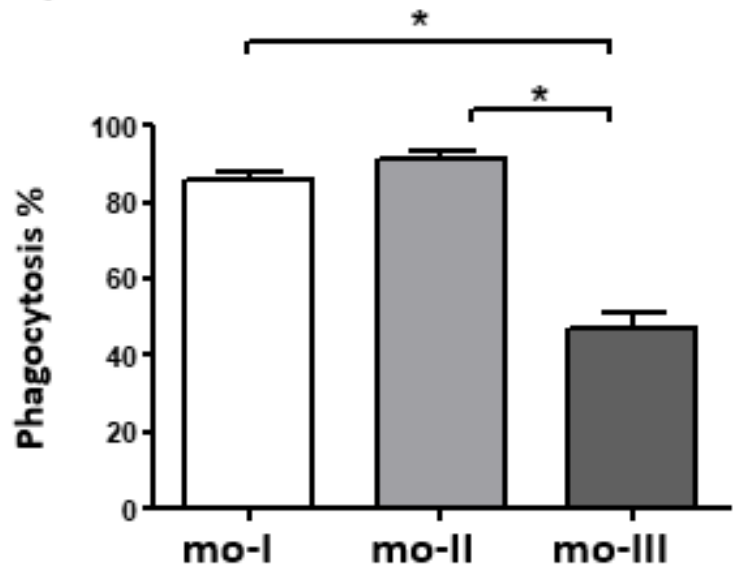

C)

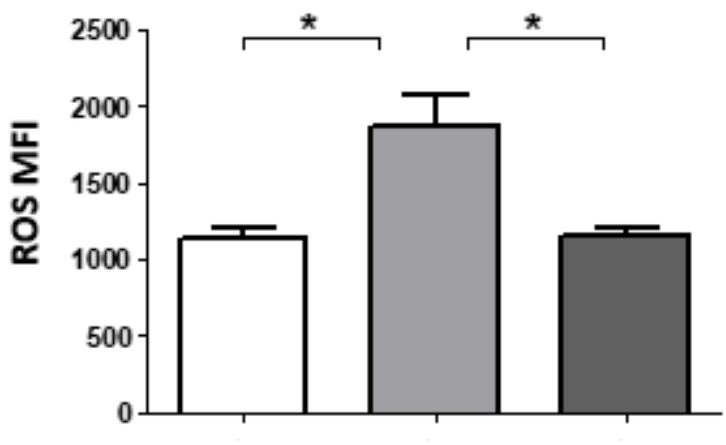

mo-I mo-II mo-III
B)

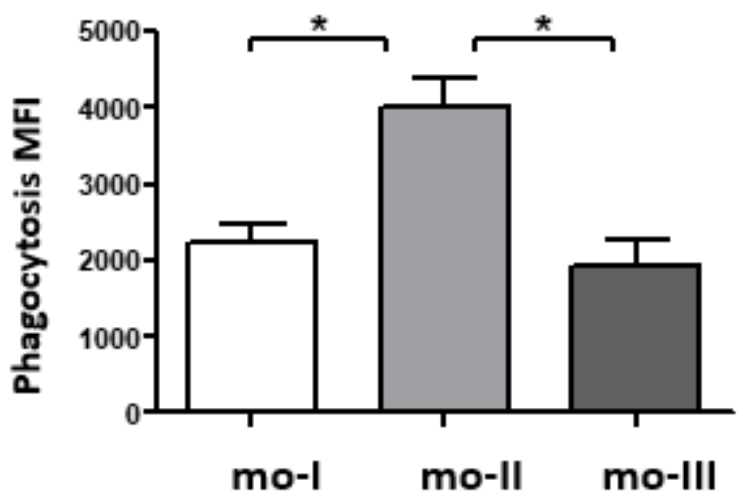

\section{Figure 5}

Phagocytosis and ROS-production capacity of camel monocyte subsets. Separated camel leukocytes were labeled with monoclonal antibodies to CD14 and MHCII. Labeled cells were incubated with heat killed FITC-labeled S. aureus bacteria. After gating on camel monocyte subsets (mo-l, mo-II, mo-III) the percentage of FITC-positive, phagocytosis-positive cells (A) and the mean fluorescence intensities (MFI) of phagocytosis-positive cells (B) was determined for each subset (means \pm SEM). (C) Parallel setups of labeled camel leukocytes loaded with the ROS-sensitive dye dihydrorohdamin-123 (DHR-123) were stimulated with heat killed S. aureus bacteria. The reactive oxygen-dependent generation of rhodamin 123 was recorded flow cytometrically for gated camel monocyte subsets as the mean cellular fluorescence (ROS MFI, mean \pm SEM, $n=21$ animals.) Differences between groups were calculated using the one-way ANOVA and were considered significant $(*)$ if $p<0.05$. 


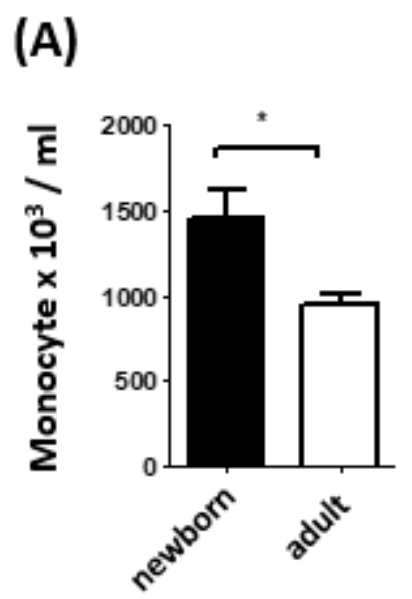

(B)

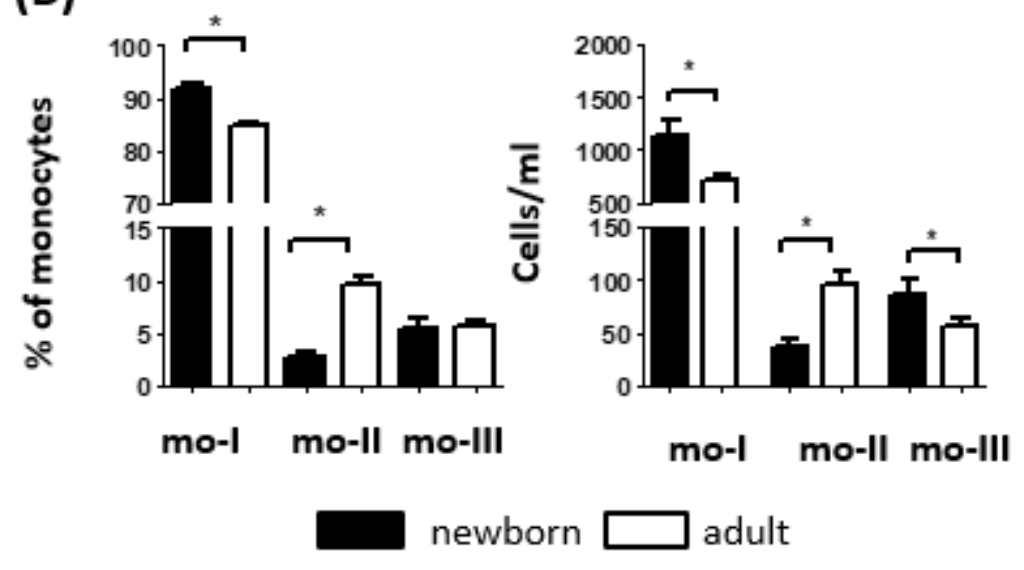

Figure 6

Monocyte subsets in newborn and adult camels. (A) Total numbers of monocytes/ ml blood after microscopic counting of total leukocytes and flow cytometric determination monocyte percentages among leukocytes (mean $\pm S E M, n=62$ animals). Difference between groups was calculated using the $t-$ test and was considered significant $(*)$ if $p<0.05$. (B) Percentages and cell counts / $\mathrm{ml}$ blood of three camel monocyte subsets (mo-l, mo-II, mo-III) of newborn ( $n=23$ animals) and adult $(n=62$ animals) camels were calculated and presented as mean \pm SEM. Difference between groups was calculated using the t-test and was considered significant $(*)$ if $p<0.05$. 

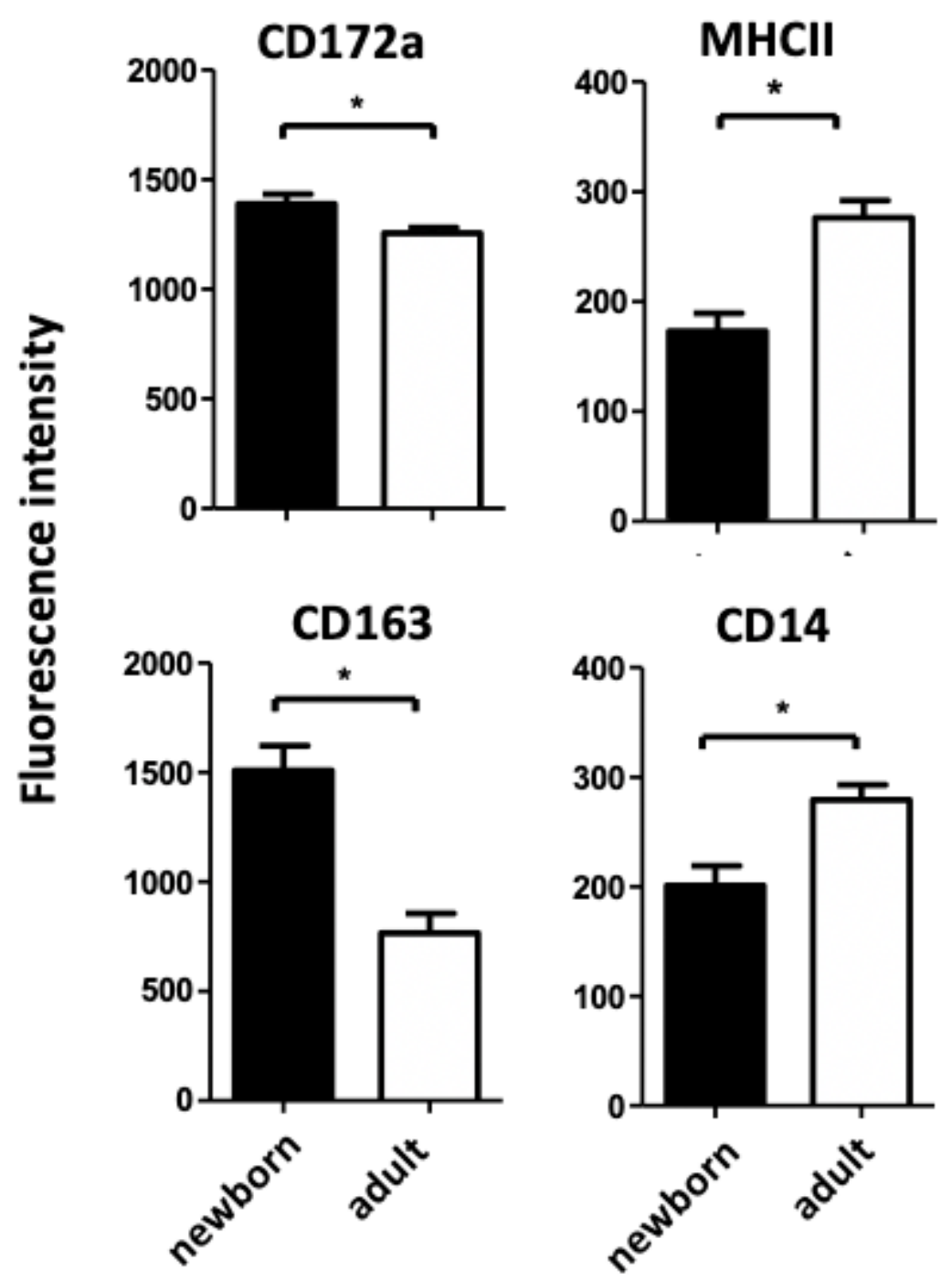

Figure 7

Expression densities of cell surface molecules on newborn and adult camel monocytes. Separated camel leukocytes were labeled with monoclonal antibodies to CD14, CD172a, MHCII and CD163 and analyzed by flow cytometry. After gating on camel monocyte subsets, expression levels of CD14, CD172a, MHCII and CD163 were measured as mean fluorescence intensities of analyzed markers and were shown as mean \pm SEM. * indicates a significant difference $(p$ value $<0.05)$ between groups as analyzed by the $t-$ test. 